\title{
Aplicação da Teoria das Filas, CoM Prioridades, ì Área de Perícia Documenstocópica de uma Superintendência da Polícia Federal
}

\author{
Roosevelt Alves Fernandes Leadebal Junior
}

Universidade Federal de Pernambuco - DF

\begin{abstract}
RESUMO:
O presente trabalho se propõe a analisar o comportamento do sistema de atendimento da perícia documentoscópica em uma unidade da Perícia da Polícia Federal, observando suas filas de atendimento de alta e baixa prioridades. Para tanto, modelou-se o sistema atual e realizou-se testes no modelo para perceber o comportamento do sistema no período analisado pela modelagem, que compreende janeiro de 2017 a junho de 2017 . As chegadas e os atendimento não foram rejeitados pelos testes de aderência (qui-quadrado). Os resultados obtidos fornecem uma ferramenta de análise e previsão de medidas na gestão, necessárias para evitar gargalos no sistema. Na medida que demonstram alterações nas chegadas prioritárias, a busca pela estabilidade do sistema $(\mathrm{m} / \mathrm{m} / \mathrm{c})$ consegue dimensionar a equipe de atendimento necessária para reagir àquela mudança.
\end{abstract}

Palavras-chave: Polícia federal. Perícia criminal federal. Teoria das filas. Prioridades.

\section{INTRODUÇÃo}

A Polícia Federal - PF faz-se presente em todas as unidades da Federação através de uma superintendência regional - SR. Dentro de sua estrutura organizacional, a área da perícia é conhecida como Setor Técnico-Científico - Setec, subordinada direta e administrativamente ao superintendente. 
No entanto, o processo de atendimento das requisições periciais segue um fluxo diverso do administrativo. Com menor burocracia, as requisições periciais são elaboradas pela autoridade policial de uma delegacia, dentro da estrutura administrativa de uma SR, diretamente para o Setec.

Cabe esclarecer que as requisições periciais se dão em virtude do estabelecido no art. 158 do Código de Processo Penal - CPP, o qual estabelece que, quando a infração deixar vestígios, será indispensável o exame de corpo de delito, direto ou indireto, não podendo suprir a confissão do acusado. Ademais, é importante salientar que a atuação do perito também foi estabelecida no mesmo Código, quando no seu art. 159, e estabelece que o exame de corpo de delito e outras perícias sejam realizados por perito oficial, portador de diploma de curso superior.

Conjugado aos dispositivos legais supramencionados, a Constituição Federal - CF de 1988, no $\$ 1^{\circ}$ de seu art. 144, estabelece as atribuições da PF. Portanto, as requisições periciais que chegam ao Setec possuem os elementos outrora destacados, para que a perícia da corporação possa examinar a materialidade e buscar a autoria.

Diante da amplitude de tipos penais, a perícia da PF atua em diversas áreas da ciência, conforme a necessidade de exame do corpo de delito (prova/vestígio) apreendido. Portanto, para facilitar o atendimento, a perícia da PF é dividida em áreas de atuação, de acordo com o exame pericial necessário. Por exemplo, livros contábeis e extratos bancários são examinados pela área financeira; obras públicas são examinadas pela área de engenharia; mídias eletrônicas são analisadas pela área de informática; documentos e assinaturas são avaliados pela área de documentoscopia, etc.

Diante do exposto, a presente pesquisa selecionou a perícia documentoscópica do Setec de uma SR da PF. Especificamente, a área documentoscópica, objeto de investigação do presente estudo examina a autenticidade de documentos e assinaturas, os métodos e ferramentas de falsificação, bem como trabalha na identificação da autoria de assinaturas apostas em documentos oficiais falsificados. 
A perícia documentoscópica foi aqui escolhida por representar a perícia com cinco qualidades básicas, quais sejam: 1) estar presente em todas as unidades da perícia da PF; 2) deter participação permanente e contínua nas pendências; 3 ) possuir a maior quantidade de peritos capacitados em realizar seus exames em todas as unidades; 4) equivaler a aproximadamente $20 \%$ da média de produção mensal nacional; e 5) representar aproximadamente $10 \%$ das pendências na fila de atendimento de todo o sistema pericial, conforme os gráficos 1 e 2 abaixo. Por outro lado, não foi verificado nenhum estudo de modelagem apontando para a gestão no atendimento da perícia documentoscópica.

Gráfico 1 - Número de pendências periciais de todas as áreas do Brasil

Brasil (71 unidades) - Abril/2016 a Março/2019 - Mensal

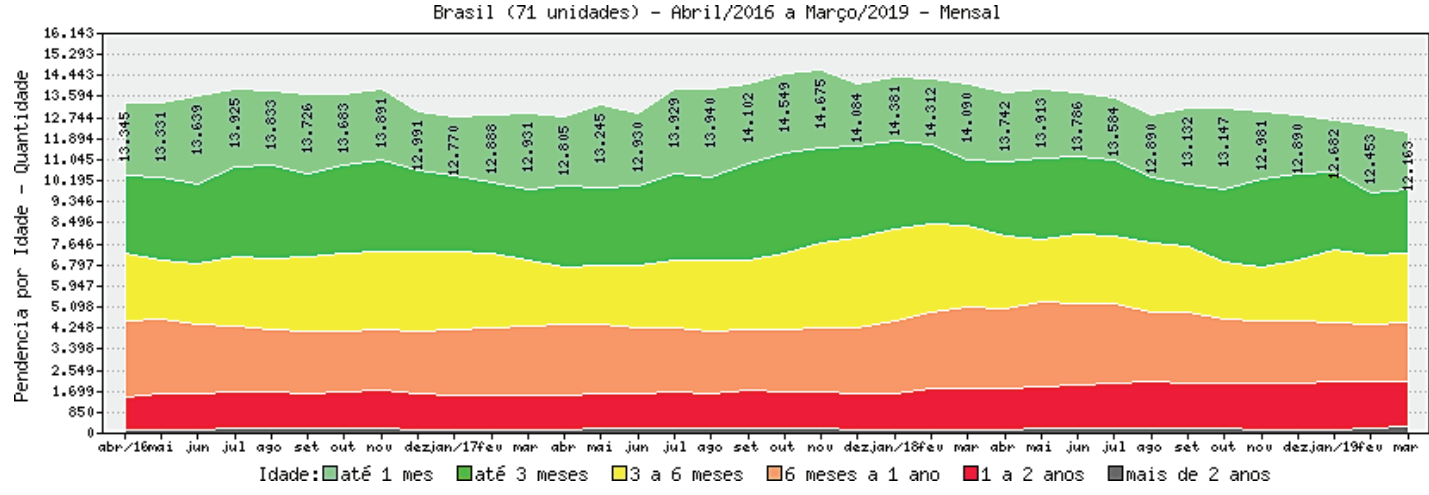

Fonte: Siscrim/Ditec/PF (2019).

Gráfico 2 - Número de pendências de perícias documentoscópica no Brasil

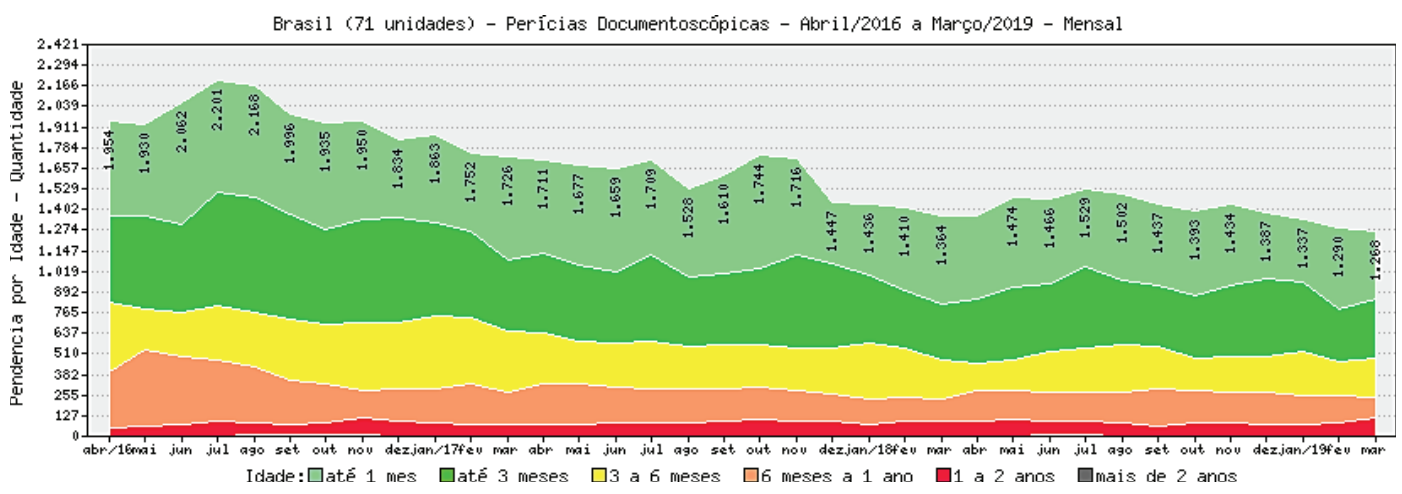

Fonte: Siscrim/Ditec/PF (2019). 


\section{ReFerencial Teórico}

As filas são conhecidas por todos e existem em vários setores, afetando o cotidiano. Por isso, é importante estudar suas características, buscando entender sua dinâmica.

O presente estudo modela a fila de requisições periciais da área de documentoscopia no Setor Técnico-Científico - Setec da superintendência regional de um estado brasileiro, não para deixar de existir uma fila, mas, conforme Prado (2004), a fim de "obter um balanceamento adequado que permita um atendimento aceitável pelo melhor custo benefício" (p. 20). Assim, como a Teoria das Filas é um método analítico, por meio de fórmulas matemáticas, as linhas que se seguem buscaram aplicar os conceitos e as fórmulas pertinentes, com o intuito de identificar as deficiências do sistema de atendimento pericial e um possível desequilíbrio na capacidade de atendimento da demanda.

Segundo Prado (2004, p.18), “o objetivo da modelagem de sistemas é, conhecendo o cenário, as características e as necessidades de todos os envolvidos, obter o melhor dimensionamento e desempenho", ou seja, torna-se importante, primeiro, modelar um sistema para que se possa entender seu fluxo de processo, mensurar uma demanda, quantificar o número de pessoas necessárias para o atendimento, medir o tempo do processamento de algum produto, etc., para que se possa melhorar um sistema.

Segundo Hillier e Lieberman (2013), no processo básico de filas, os clientes que necessitam de atendimento são gerados ao longo do tempo por uma fonte de entradas, entrando no sistema de filas epegando uma fila; e, em certos momentos, um integrante da fila é selecionado para o atendimento por alguma regra conhecida como disciplina da fila [...], sendo que o atendimento necessário é então realizado para o cliente pelo mecanismo de atendimento, após o qual o cliente deixa o sistema de filas (HILLIER; LIEBERMAN, 2013, p. 729).

O presente estudo adotou a metodologia do processo de filas elementar de Hillier e Lieberman (2013), onde os tempos entre as chegadas e os tempos de atendimento sejam independentes e identicamente distribuídos, conforme demonstrado na Figura 1. 
Figura 1 - Sistema de filas elementar, onde cada cliente é indicado por um C e cada atendente por um $S$

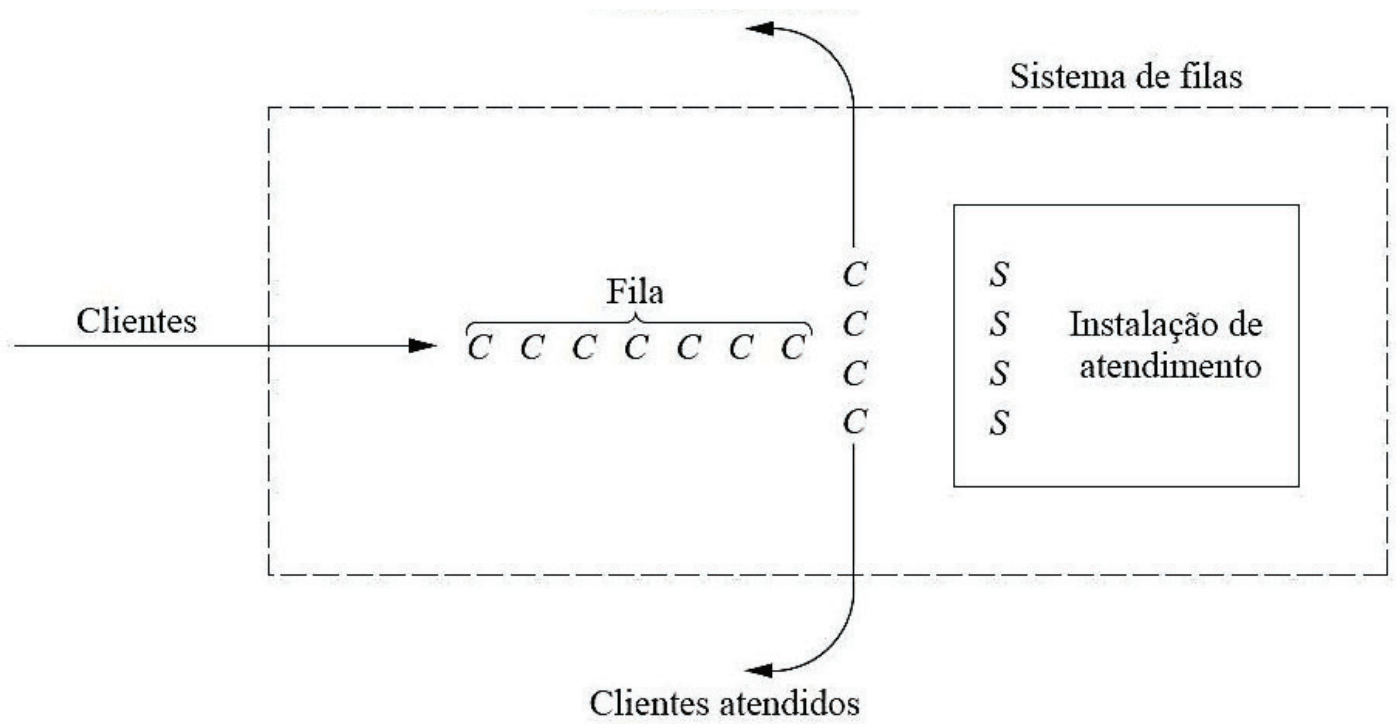

Fonte: Hillier e Lieberman (2013, p. 731).

Os modelos de filas mais elementares partem do pressuposto que as entradas (chegada dos clientes) e as saídas (clientes atendidos que saem) do sistema de filas se dão conforme o processo de nascimento (chegada dos clientes) e morte (partida do cliente atendido).

Para tanto, Hillier e Lieberman (2013) destacam três hipóteses, quais sejam:

1) $X(t)=n(\lambda)$ : a distribuição de probabilidade atual do tempo remanescente até o próximo nascimento (chegada) é exponencial com parâmetros $\lambda_{\mathrm{n}}(\mathrm{n}=0,1,2 \ldots)$;

2) $X(t)=n(\mu)$ : a distribuição de probabilidade atual do tempo remanescente até a próxima morte (saída) é exponencial com parâmetros $\mu_{n}(n=0,1,2 \ldots)$; e

3) A variável aleatória da hipótese "1" e a variável aleatória da hipótese "2" são mutuamente independentes. A próxima transição no estado do processo é:

$\mathrm{nn}+1$ (um único nascimento)

ou então 


$$
\text { nn - 1(uma única morte) }
$$

$\mathrm{Na}$ prática, tal princípio quer dizer que a taxa que entra no sistema é igual àquela que sai do sistema, culminando na equação de equilíbrio, servindo para um ou mais atendentes, conforme evidenciado na Figura 2, a seguir:

Figura 2 - Diagramas de taxas para o modelo $\mathrm{M} / \mathrm{M} / \mathrm{c}$

(a) Caso com um único atendente $(s=1)$

$$
\begin{array}{ll}
\lambda_{n}=\lambda, & \text { para } n=0,1,2, \ldots \\
\mu_{n}=\mu, & \text { para } n=1,2, \ldots
\end{array}
$$

Estado:
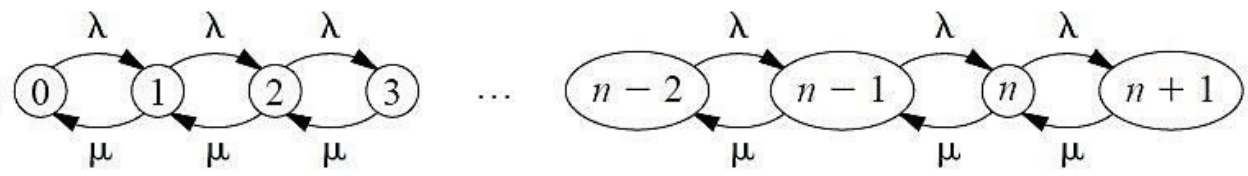

(b) Caso com vários atendentes $(s>1)$

$$
\begin{aligned}
\lambda_{n} & =\lambda, \quad \text { para } n=0,1,2, \ldots \\
\mu_{n} & = \begin{cases}n \mu, & \text { para } n=1,2, \ldots, s \\
s \mu, & \text { para } n=s, s+1, \ldots\end{cases}
\end{aligned}
$$

Estado:
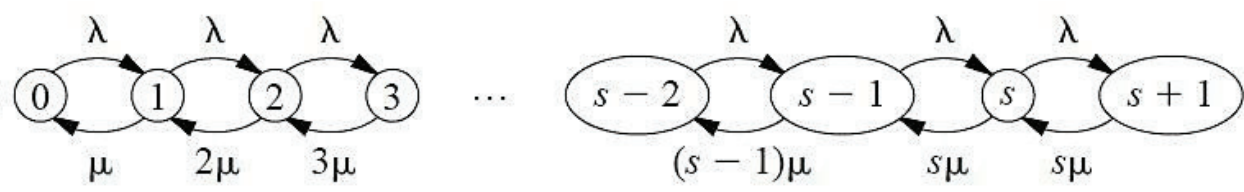

Fonte: Hillier e Lieberman (2013, p. 746).

A distribuição de Poisson modela uma variável aleatória discreta que trata da possibilidade de uma série de eventos ocorrerem em certo período de tempo, considerando que tais eventos ocorrem independentemente.

De fato, no caso aqui analisado, as requisições periciais chegam ao Setec de forma independente, i.e., a nova não depende da anterior. Afinal, cada requisição pericial está relacionada a um tipo de exame de corpo de delito e de um determinado fato criminoso.

Segundo Hillier e Lieberman (2013), um modelo de filas de disciplina com prioridades ocasiona que os integrantes da fila se ordenem da prioridade mais alta para mais baixa. Assim, os clientes são selecionados para serem atendidos na ordem de sua classe de prioridade.

Existem dois modelos de prioridade, quais sejam: 1) sem 
preempção; e 2) com preempção. No primeiro caso, o cliente que está sendo atendido não tem seu atendimento interrompido e não volta para fila mesmo com a chegada de um cliente com prioridade; ou seja, o atendimento ocorre sem interrupção. No segundo caso, o cliente com menor prioridade que está sendo atendido tem seu atendimento interrompido e volta para fila, para que o cliente com maior prioridade seja atendido.

Diante do conceito em questão, tem-se a modelagem do atendimento de prioridades não preemptivas, que dispõe da fórmula a seguir, nas planilhas de Microsoft Excel elaboradas por Hillier e Lieberman (2013):

Figura 3 - Modelo de prioridades não preemptivas

$$
\begin{aligned}
& W_{k}=\frac{1}{A B_{k-1} B_{k}}+\frac{1}{\mu}, \quad \text { para } k=1,2, \ldots, N, \\
& \text { em que } \quad \begin{aligned}
A & =s ! \frac{s \mu-\lambda}{r^{s}} \sum_{j=0}^{s-1} \frac{r^{j}}{j !}+s \mu, \\
B_{0} & =1, \\
B_{k} & =1-\frac{\sum_{i=1}^{k} \lambda_{i}}{s \mu},
\end{aligned}
\end{aligned}
$$

$s=$ número de atendentes,

$\mu=$ taxa média de atendimento por atendente ocupado,

$\lambda_{i}=$ taxa média de chegada for classe de prioridades $i$,

$$
\begin{aligned}
& \lambda=\sum_{i=1}^{N} \lambda_{i}, \\
& r=\frac{\lambda}{\mu} .
\end{aligned}
$$

Fonte: Hillier e Lieberman (2013, p. 765).

Além da necessidade de se modelar as informações anteriores, segundo Prado (2004), um sistema de filas apresenta as seguintes variáveis aleatórias fundamentais, que são objetos do presente estudo: 
a) Processo de chegada:

- $\lambda=$ taxa média de chegada; $\mathrm{e}$

- $\quad \mathrm{IC}=$ intervalo médio entre chegadas.

b) Informações referentes à fila:

- $\quad \mathrm{TF}=$ tempo médio de permanência na fila; $\mathrm{e}$

- $\mathrm{NF}=$ número médio de clientes na fila.

c) Informações do processo de atendimento:

- $\quad \mathrm{TA}=$ tempo médio de atendimento;

- $\quad c=$ capacidade de atendimento ou quantidade de servidores;

- $\quad \mathrm{NA}=$ número médio de clientes que estão sendo atendidos; e

- $\mu=$ taxa média de atendimento de cada servidor.

d) Variáveis do sistema (fila + atendimento):

- $\mathrm{TS}=$ tempo médio de permanência no sistema; $\mathrm{e}$

- NS = número médio de clientes no sistema.

Segundo Kendall-Lee (1951), seis características descrevem um sistema de filas: $\mathrm{A} / \mathrm{B} / \mathrm{c} / \mathrm{K} / \mathrm{m} / \mathrm{Z}$, sendo necessário conhecer anteriormente cada um dos seis componentes para especificar um sistema de filas, conforme se segue: A: distribuição dos tempos entre as chegadas; B: distribuição dos tempos de serviço; c: capacidade de atendimento (quantidade de servidores); K: capacidade máxima do sistema (número máximo de clientes no sistema - é omitido quando for infinito); m: tamanho da população que fornece clientes (é omitido quando for infinito); e Z: disciplina da fila (é omitido quando for Fifo - First In, First Out), ou seja, o primeiro elemento a chegar é o primeiro a ser atendido. 
O interessante é que se a distinção entre as diferentes classes de clientes de prioridades for ignorada, implica que todos os clientes chegam conforme um processo de entrada Poisson, além de todos terem a mesma distribuição exponencial de atendimento. Ademais, com base em Hillier e Lieberman (2013), os dois modelos com prioridade e sem prioridades são idênticos ao modelo $\mathrm{M} / \mathrm{M} / \mathrm{c}$ estudado, em que o primeiro $\mathrm{M}$ indica que a chegada tem distribuição markoviana, ou seja, exponencial, o segundo $\mathrm{M}$ indica que o atendimento também segue uma distribuição exponencial e o $c$ indica o número de servidores ou atendentes do sistema, exceto pela ordem que são atendidos.

Ainda nessa mesma linha, Andrade (2000) afirma que um sistema de filas apresenta algumas das características que, aplicadas ao sistema de filas das requisições periciais documentoscópicas, pode-se interpretar desta forma: a) o processo de chegada das requisições periciais é variado, com grandes fluxos em curto espaço de tempo, seja pelo envio de várias requisições ao mesmo tempo, seja em virtude de operações ou flagrantes, acarretando acúmulo de expedientes; b) o modelo de serviços prestados: é o tempo que o perito realiza o atendimento; c) o números de servidores trata da quantidade de peritos que podem atender às requisições ao mesmo tempo, que é finita; d) a capacidade do sistema por limitação física e de servidores é classificada como finita; e) o tamanho da população é o número de requisições de perícia que podem chegar no sistema e infinito; ef) a disciplina da fila é a Fifo, neste caso será FCFS (Fisrt Come, Fisrt Served), na qual o primeiro a chegar é o primeiro a ser atendido; mas também é utilizada a LCFS (Last Come, Firsts Served), em que o último individuo a chegar é o primeiro a ser atendido, por questão de prioridade alta. Neste trabalho será utilizada a expressão FCFS para o atendimento de prioridade baixa e LCFS quando a prioridade for alta.

O Gráfico 3 apresenta as pendências documentoscópicas nos últimos três anos, mês a mês, sendo observado um aumento significativo após o mês de outubro de 2017, com pico entre os meses de dezembro de 2018 e janeiro 2019. Dessa forma, é relevante a realização deste estudo, tendo em vista o aumento das pendências de perícias documentoscópicas no setor técnico-científico da superintendência regional da Polícia Federal da região avaliada neste estudo. 
Aplicação da teoria das filas, com prioridades, à área deperícia documenstocópica...

Gráfico 3 - Número de pendências de perícias documentoscópicas no setor técnico-científico da superintendência regional da Polícia Federal do estado avaliado

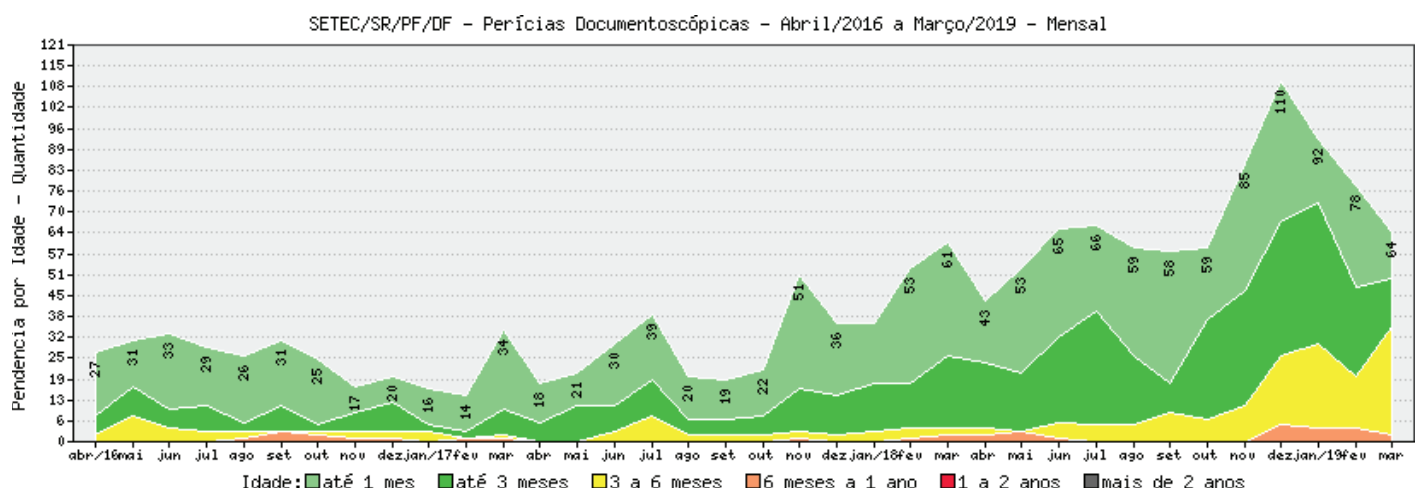

Fonte: Siscrim/Dietc/PF (2019).

É importante destacar o posicionamento de Moreira (2010), que a fila não se forma tão somente por um problema de capacidade de atendimento, mas também devido à variabilidade tanto no intervalo entre as chegadas como no tempo de atendimento, afirmação que corrobora com a atual situação do sistema, pois, em abril de 2019, identificou-se uma fila com 64 requisições pendentes. Ou seja, o sistema continua com falhas.

A partir dessas notaçóes, esta pesquisa busca por um modelo de estabilidade no sistema de atendimento pericial e encontra nos estudos de Hillier e Lierberman (2013) o processo de nascimento-e-morte (modelo $\mathrm{M} / \mathrm{M} / \mathrm{c}$ ), a base de cálculo para dimensionar a equipe de atendimento, o tempo das filas e ociosidade dos servidores, inclusive analisando as filas com as duas classes de prioridade, alta e baixa.

\section{Descrição do Caso Real}

\subsection{Modelagem ReAL}

O modelo aqui adotado teve por objetivo encontrar o melhor dimensionamento da equipe de atendimento para as requisições periciais, a partir da análise das filas de pendências da área documentoscópica do Setor Técnico-Científico - Setec da superintendência regional - SR da Polícia Federal - PF de um estado brasileiro (BRASIL, 2018). 
Vale ressaltar que estudos de modelagem que direcionem a Diretoria Técnico-Científica - Ditec na distribuição do pessoal efetivo na superintendência regional da PF são escassos.

Os dados analisados foram extraídos do Sistema Nacional de Gestão de Atividades de Criminalística - Siscrim, no período de janeiro de 2017 a junho de 2017 (dias úteis), especificamente de uma unidade pericial na área de perícia documentoscópica, contendo seus respectivos registros históricos das chegadas das requisições periciais, do período de atendimento de cada requisição, do número de servidores que promoveram algum atendimento e sua classificação de prioridade ou não.

O período de avaliação utilizado neste estudo foi definido porque nesse período o autor deste artigo ocupava o cargo de chefia desse setor e, dessa forma, optou-se por não avaliar o período de chefia de outra pessoa. Por outro lado, a amostra foi suficiente para caracterizar o processo com dados reais. Além disso, foi realizado o teste de qui-quadrado de aderência, do qual se comparou os valores observados dos dados de chegada com os valores esperados, sendo possível afirmar, com 95\% de confiança, que os dados de chegadas seguem uma distribuição de Poisson, não tendo, portanto, interferência de sazonalidade.

Por esse motivo, torna-se importante mapear o fluxo de atendimento pericial no Setec para entender cada etapa que a Teoria das Filas faz menção.

Portanto, cabe explicar que quando há necessidade de um exame pericial em um corpo de delito apreendido, os usuários do sistema encaminham tal material para a área da perícia na PF (Setor Técnico-Científico - Setec), juntamente com um documento (ofício) solicitando respostas para esclarecer o vínculo daquela materialidade com o fato investigado. $\mathrm{O}$ exame pericial visa a identificar o material (descrevendo-o), analisando-o com o intuito de obtenção da autoria, da autenticidade, dos métodos de fabricação/falsificação, entre outros. Vale destacar que os usuários desse sistema são: a autoridade policial, o membro do Ministério Público - MP ou a autoridade judiciária.

Nesse ínterim, ao ser recebida a requisição de exame pericial do referido setor pela secretaria administrativa, o documento é cadastrado 
no Siscrim, onde se tem a identificação de sua origem, do requisitante, do Inquérito Policial - IPL ou outro procedimento investigativo, da data de chegada, do seu nível de prioridade, de sua área de exame, de sua complexidade e de seu prazo para atendimento para, posteriormente, ser encaminhado ao gestor responsável pela área da perícia, o qual distribui a requisição, indicando o perito responsável para a realização do exame pericial. O Perito Criminal Federal - PCF indicado para o atendimento analisa o material, identifica se é uma requisição urgente ou não, identifica a viabilidade de realização da perícia, realiza o exame pericial e, posteriormente, elabora o respectivo laudo, devolvendo para a secretaria todo o material encaminhado, juntamente com o respectivo laudo, registrando o término do atendimento.

Por sua vez, a secretaria fica responsável pela entrega do laudo (ou outro documento técnico) e pelos materiais examinados para o respectivo requisitante (usuário), realizando os lançamentos das datas do término do atendimento e da entrega do material, conforme evidenciado na Figura 3.

Figura 3 - Fluxo de atendimento Setec

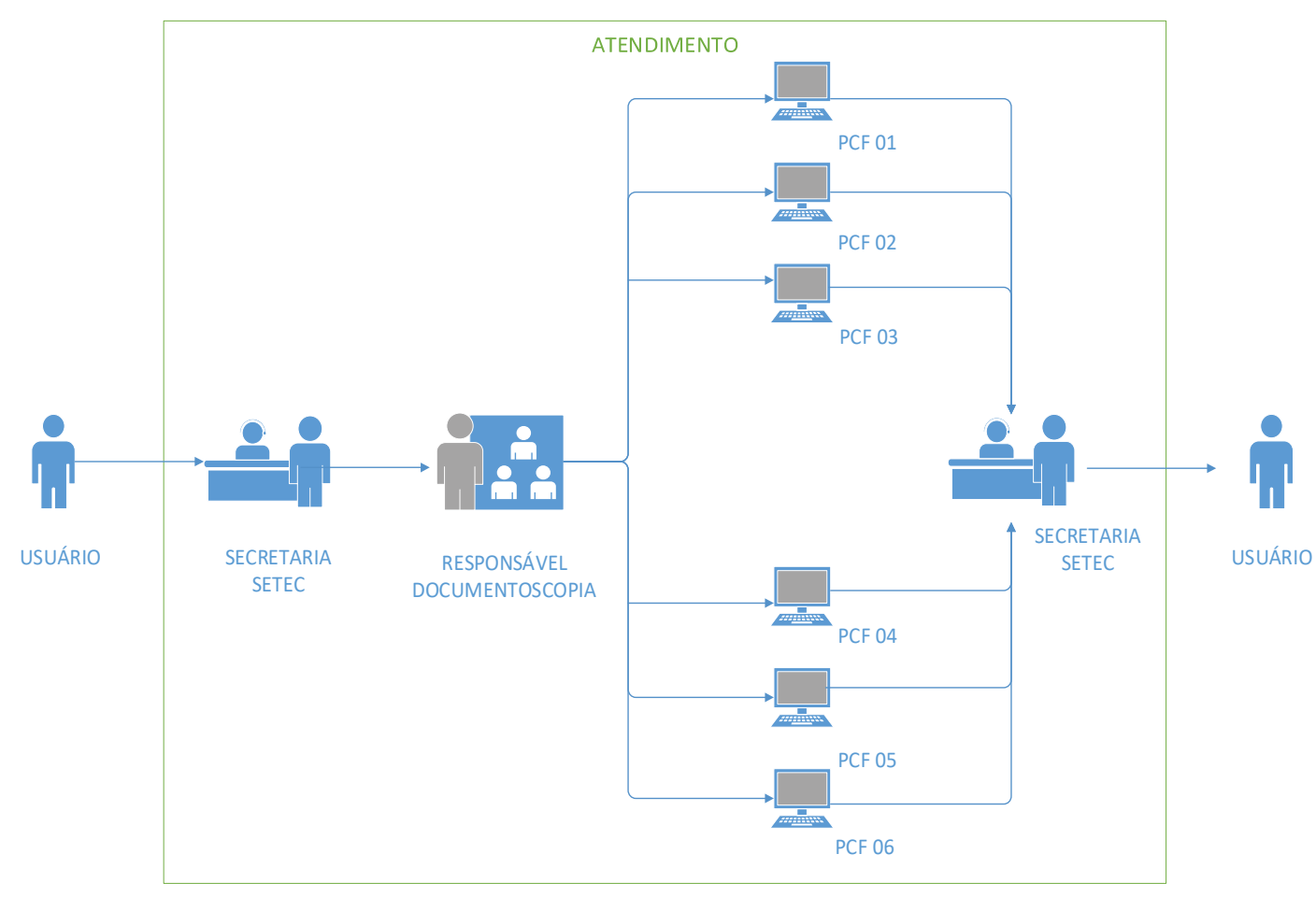

Fonte: elaborado pelo autor

A partir dessas notações, esta pesquisa busca por um mode- 
lo de estabilidade no sistema de atendimento pericial e encontra nos estudos de Hillier e Lierberman (2013) o processo de nascimento-e-morte (modelo $\mathrm{M} / \mathrm{M} / \mathrm{c}$ ) a base de cálculo para dimensionar a equipe de atendimento, o tempo das filas e ociosidade dos servidores, inclusive analisando as filas com as duas classes de prioridade, alta e baixa.

As chegadas no sistema são classificadas quanto à prioridade pela sua criticidade (alta, ou baixa). A disciplina no atendimento pericial segue a FCFS, na qual o primeiro a chegar é o primeiro a ser servido. Foram identificados poucos casos prioritários ( $9 \%$ da demanda total) na área de documentoscopia e sem preempção no seu atendimento, atendidos pela ordem LCFS.

Segundo Hillier e Lieberman (2013), um modelo de filas de disciplina com prioridades ocasiona que os integrantes da fila se ordenam da prioridade mais alta para mais baixa. Assim, os clientes são selecionados para serem atendidos na ordem de sua classe de prioridade. Existem dois modelos de prioridade, quais sejam: 1) sem preempção (atendimento não é interrompido para atendimento da prioridade); e 2) com preempção (atendimento interrompido para atendimento da prioridade). $\mathrm{O}$ estudo analisou o primeiro caso.

Conforme Chwif e Medina (2014), a última etapa do processo de modelagem de dados é qualificarmos a aderência do modelo, ou seja, verificar se as distribuições são estatisticamente adequadas para representar os dados coletados.

As análises consistiram na execução de teste de hipóteses estatísticos com o intuito de verificar se as chegadas seguem a distribuição de Poisson e se os tempos de atendimento seguem a distribuição exponencial. Para isso, foi realizado o teste qui-quadrado de aderência, por ser um teste confiável para confirmação das hipóteses de distribuição para modelagem e simulação de eventos discretos. Além disso, na execução do teste estatístico considerado, fez-se uso do nível de 5\% de significância (o mesmo que 95\% de confiança). E ainda, o software utilizado na execução das análises estatísticas presentes foi o $\mathrm{R}$ versão. 3.5.0 (R, 2018). 


\subsubsection{Modelagem CHEgadAS}

Considerando que o intuito é verificar se o número de chegadas segue uma distribuição de Poisson, para tal finalidade foi utilizado o teste qui-quadrado de aderência, no qual se compararam os valores observados dos dados de chegadas com os valores esperados dessas mesmas chegadas, verificando se que os mesmos provêm de uma distribuição de Poisson. Esse teste, como visto em Santos (2003), se demostra uma verificação eficaz especificamente para o sistema de filas, o qual, na sua maioria, segue uma distribuição discreta de probabilidade de Poisson.

Cita-se como exemplo a distribuição para taxa de chegada, ou seja, o tempo médio em que chega o indivíduo para alocação na fila, representado pelo parâmetro (lambda), sendo assim estaremos objetivando testar se as chegadas seguem ou não uma distribuição de Poisson (SANTOS, 2003), como já determinado no nosso regime de fila sendo $\mathrm{M} / \mathrm{M} / \mathrm{c}$.

A Tabela 1 e o Gráfico 4 apresentam os valores observados e esperados, para os quais foi obtido um p-valor $=0,2304>0,01$.

Assim, não se rejeitou a hipótese de que as chegadas seguem uma distribuição de Poisson ao nível de 5\% de significância (o mesmo que $95 \%$ de confiança). Como o número médio de chegadas foi igual a 1,10 por dia útil, é possível afirmar, com 95\% de confiança, que os dados de chegadas seguem uma distribuição de Poisson com parâmetro .

Para enfatizar ainda mais a interpretação outrora apontada, o Gráfico 4 compara a função de distribuição dos dados observados com a função de distribuição teórica da Poisson $\operatorname{com} \lambda=1,10$. Nesse sentido, é possível observar que os gráficos das funções de distribuição observada e teórica estão bem próximos, enfatizando ainda mais o resultado obtido pelo teste qui-quadrado e a respectiva interpretação obtida.

Assim, se as chegadas seguem uma distribuição de Poisson, tem-se que o tempo entre as chegadas segue a distribuição exponencial, com média dada por $\mathrm{E}(\mathrm{X})=$ dias. $\mathrm{E}$ ainda, o Gráfico 5 relata a taxa de chegada $\lambda$ da distribuição dos dados observados (\%), com a probabilidade de estes serem uma distribuição de Poisson $(1,10)$, do qual 
é observada uma distribuição do tempo de chegada, com frequências bem semelhantes entre o observado e o esperado.

Tabela 1 - Valores observados e esperados para as chegadas

\begin{tabular}{c|c|c|c|c}
\hline Chegadas & Observado & $\begin{array}{c}\text { Relativa Ob. } \\
(\%)\end{array}$ & Esperado & $\begin{array}{c}\text { Relativa Esp. } \\
(\%)\end{array}$ \\
\hline 0 & 42 & 33,87 & 41 & 33.13 \\
1 & 46 & 37,10 & 45 & 36,60 \\
2 & 24 & 19,35 & 25 & 20,22 \\
3 & 8 & 6,45 & 9 & 7,45 \\
4 & 2 & 1,61 & 3 & 2,06 \\
5 & 1 & 0,81 & 1 & 0,45 \\
6 & 1 & 0,81 & 0 & 0,08 \\
\hline Total & 124 & \multicolumn{5}{c}{124} & \\
\hline \multicolumn{5}{|c|}{ Fonte: elaborado pelo autor } \\
\hline
\end{tabular}

Gráfico 4 - Comparação entre a função de distribuição observada e teórica para as chegadas

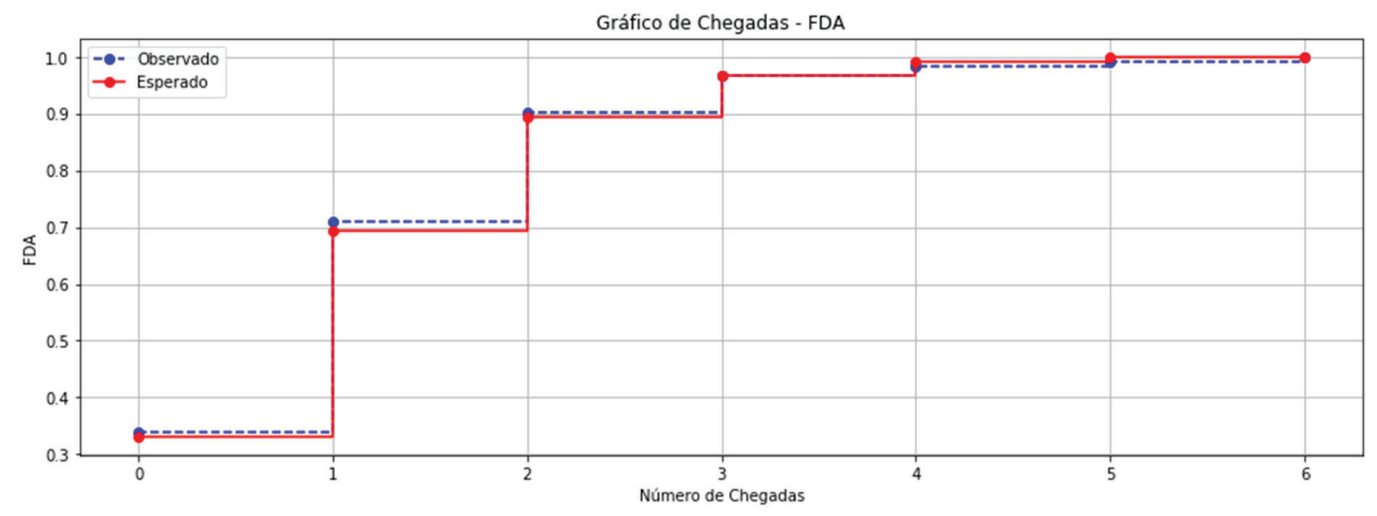

Fonte: elaborado pelo autor 
Gráfico 5 - Distribuição do tempo de chegada

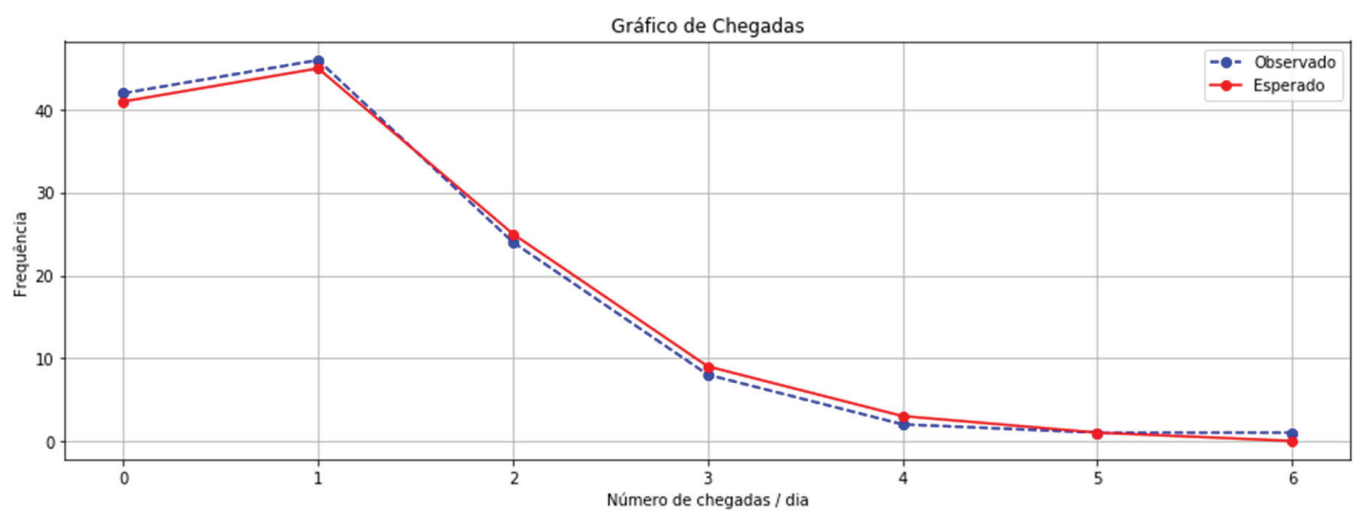

Fonte: elaborado pelo autor

\subsubsection{MODELAGEM ATENDIMENTO}

No intuito de verificar se o número de atendimentos segue uma distribuição de Poisson, também foi realizado o teste qui-quadrado de aderência. A Tabela 2 e o Gráfico 6 apresentam os valores observados e esperados, para os quais foi obtido um $p$-valor $=0,5669>0,01$. Assim, não se rejeita a hipótese de que os atendimentos seguem uma distribuição de Poisson ao nível de $5 \%$ de significância. Como o número médio de atendimentos foi igual a 2,41 dias úteis para cada requisição, é possível afirmar, com 95\% de confiança, que os dados de atendimento seguem uma distribuição de exponencial com parâmetro $\mu=0,41$.

Tabela 2 - Valores observados e esperados para os atendimentos.

\begin{tabular}{c|c|c|c|c} 
Atendimento & Observado & $\begin{array}{c}\text { Relativa } \\
\text { Ob. }(\%)\end{array}$ & Esperado & $\begin{array}{c}\text { Relativa } \\
\text { Esp. }(\%)\end{array}$ \\
\hline 1 & 45 & 39,82 & 38 & 33,89 \\
2 & 32 & 28,32 & 25 & 22,41 \\
3 & 15 & 13,27 & 17 & 14,81 \\
4 & 8 & 7,08 & 11 & 9,79 \\
5 & 4 & 3,54 & 7 & 6,47 \\
6 & 3 & 2,65 & 5 & 4,28 \\
7 & 2 & 1,77 & 3 & 2,83 \\
8 & 2 & 1,77 & 2 & 1,87 \\
9 & 1 & 0,88 & 2 & 1,24
\end{tabular}




\begin{tabular}{c|c|c|c|c}
10 & 1 & 0,88 & 1 & 0,82 \\
\hline Total & 113 & & 111 &
\end{tabular}

Fonte: elaborado pelo autor

Para enfatizar ainda mais a interpretação outrora apontada, é possível verificar no Gráfico 6 a comparação da função de distribuição dos dados observados com a função de distribuição teórica da exponencial com parâmetro $\mu=0,41$ (1/TA). De fato, o gráfico em questão evidencia que as funções de distribuição observada e teórica para os atendimentos estão próximas, enfatizando ainda mais o resultado obtido pelo teste qui-quadrado e a respectiva interpretação obtida. Logo, concluiu-se que os tempos de atendimento seguem uma distribuição exponencial com taxa dada por $\mu=1 / 2,41(0,41)$. E ainda, o Gráfico 7 confronta a distribuição dos dados observados (\%) com a probabilidade destes em uma distribuição exponencial $(0,41)$.

Gráfico 6 - Comparação entre a função de distribuição observada e teórica para os atendimentos

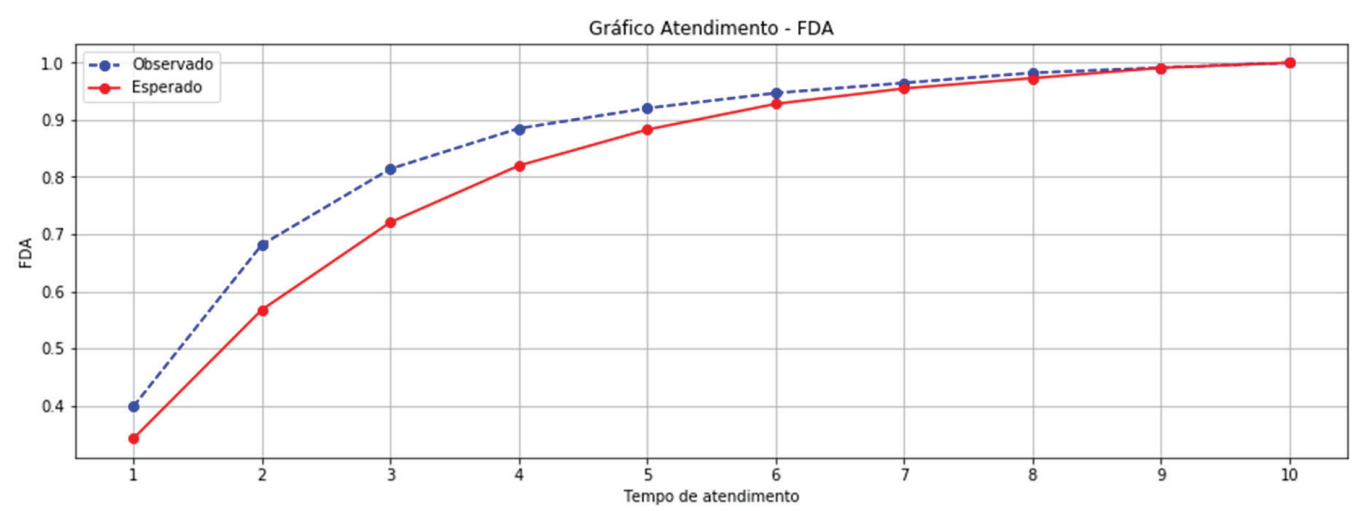

Fonte: elaborado pelo autor 


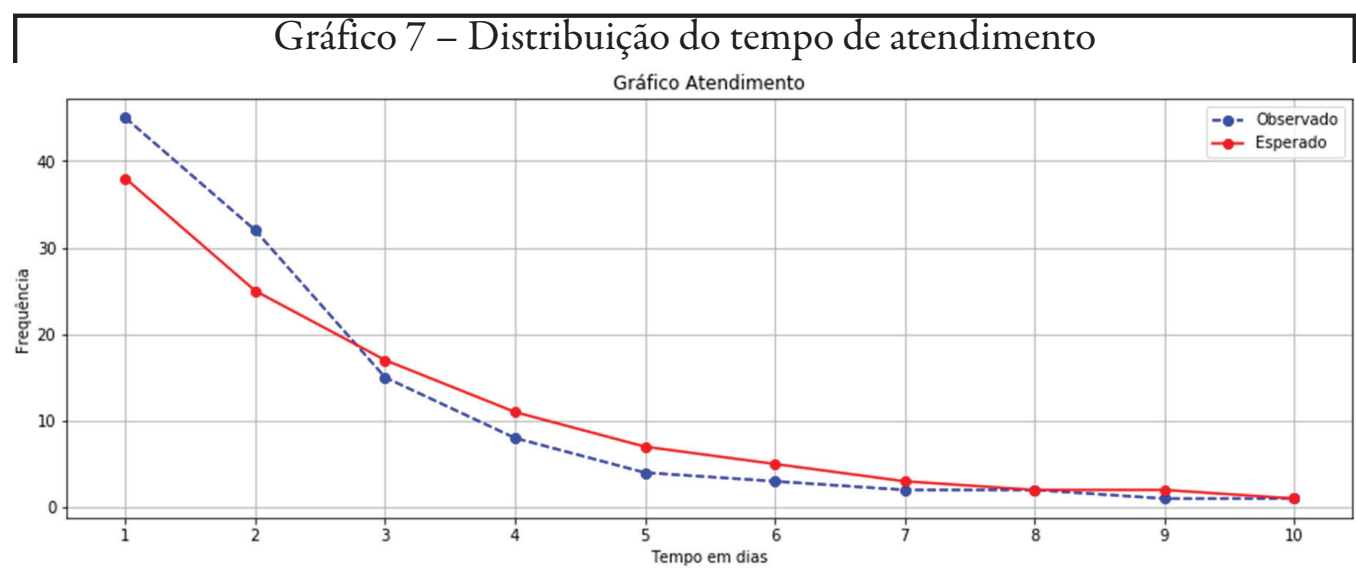

Fonte: elaborado pelo autor

\subsection{MODElAgEM ATUAL - M/M/C COM PRIORIDADES}

Com base nos parâmetros calculados anteriormente, aplicou-se o modelo M/M/c, que segundo Hillier e Lieberman (2013), tem por base o processo de nascimento-e-morte, pois possui entrada Poisson e tempo de atendimento exponenciais. O sistema em estudo possui duas classes de atendimento, quais sejam: 1) prioritária; e 2) regular, sendo que a prioritária é sem preempção.

No recebimento de cada solicitação, a secretaria do Setec classifica o grau de prioridade, entre alta ou baixa, no sistema.

Aplicando os parâmetros calculados para a fila com prioridade, sem preempção, bem como a planilha de Microsoft Excel elaborada por Hillier e Lieberman (2013), foi possível modelar tal atendimento. Importante destacar que, segundo Prado (2004), nesse caso e em qualquer sistema estável, a junção de fluxos equivale às suas somas aritméticas, ou seja, $\lambda_{3}=\lambda_{1}+\lambda_{2}$. Do mesmo modo, o desdobramento percentual de um fluxo é igual ao desdobramento aritmético do mesmo fluxo, conforme apresentado na Figura 4, dos postulados básicos.

Partindo destes postulados básicos, o somatório de $\lambda_{\mathrm{n}}$ se iguala ao valor obtido na distribuição Poisson, caracterizado pela modelagem da amostra geral. Portanto, neste estudo, considerou-se como resultado um novo fluxo de Poisson cuja taxa de chegada é o somatório das taxas de fluxo da alta prioridade e baixa prioridade. 
Figura 4 - Postulados básicos

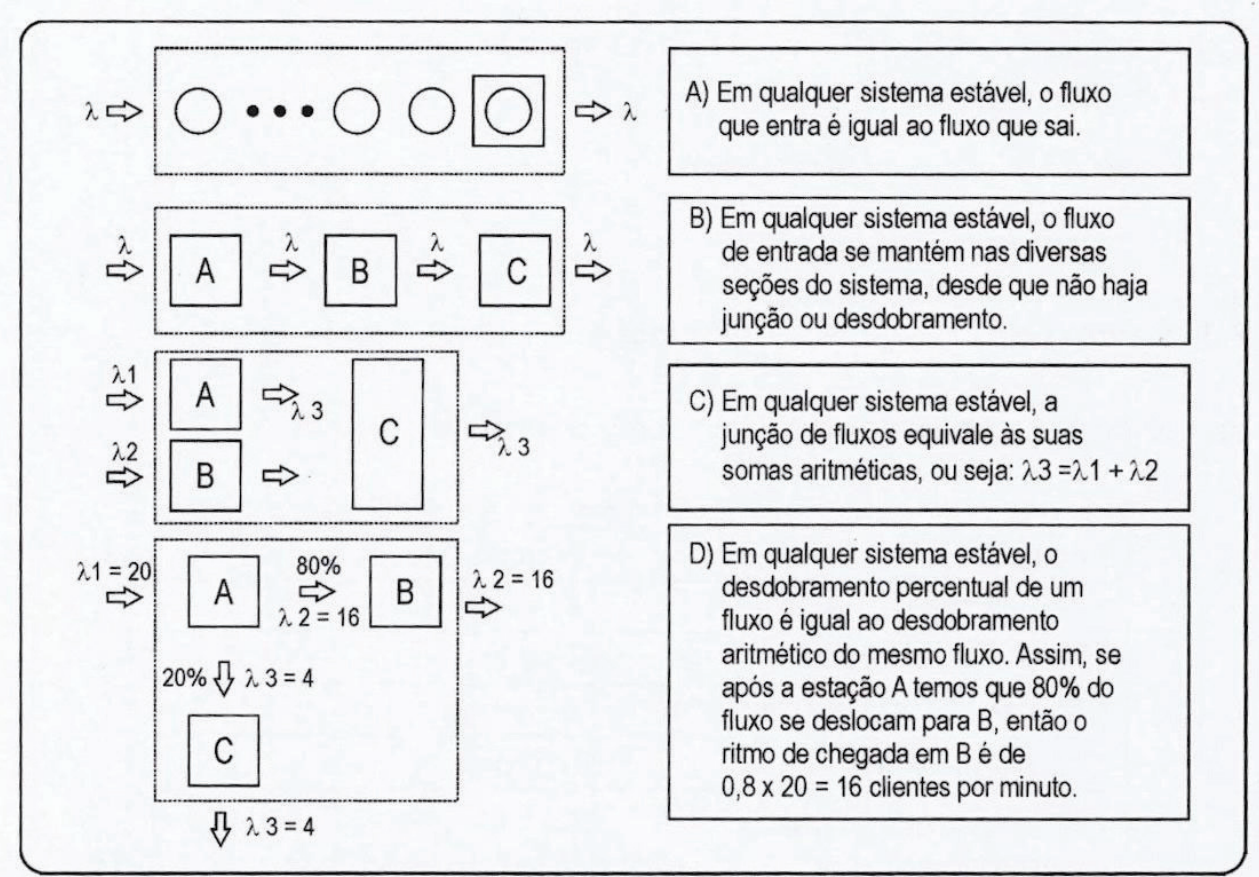

Fonte: Prado (2004, p. 50)

Assim, ao modelar o sistema pericial de atendimento, foi identificado que as chegadas com alta prioridade representam $9 \%$ de todas as chegadas mensuradas no item anterior. Na Tabela 3, a seguir, aplicando a planilha citada para duas classes de prioridade e mantendo o mesmo tempo médio de atendimento de 2,42 dias para uma requisição por servidor, é possível observar as seguintes medidas de desempenho para a disponibilização de um servidor para atender a demanda prioritária, sem preempção:

Tabela 3 - Modelo M/M/c - 2 classes de prioridade (alta ou baixa).

\begin{tabular}{|c|c|c|c|c|}
\hline Descrição & Símbolo & $\begin{array}{l}\text { Prioridade } \\
\text { Alta }\end{array}$ & $\begin{array}{l}\text { Prioridade } \\
\text { Baixa }\end{array}$ & Total \\
\hline$\lambda$ total & & 0,097 & 1,003 & 1,10 \\
\hline Número de clientes esperando & $\mathrm{E}(\mathrm{L})$ & 0,059 & 0,774 & \\
\hline Comprimento da fila & $\mathrm{E}(\mathrm{Lq})$ & 0,018 & 0,359 & \\
\hline $\begin{array}{c}\text { Tempo de espera no sistema (em dias } \\
\text { úteis) }\end{array}$ & $\mathrm{E}(\mathrm{W})$ & 0,608 & 0,771 & \\
\hline $\begin{array}{c}\text { Tempo de espera na fila (em dias } \\
\text { úteis) }\end{array}$ & $\mathrm{E}(\mathrm{Wq})$ & 0,195 & 0,358 & \\
\hline Fator de utilização do servidor & $\mathrm{E}(\mathrm{P})$ & & & 0,454 \\
\hline
\end{tabular}

Fonte: elaborado pelo autor 
A partir dos resultados acima, é possível afirmar que o atendimento com um servidor para todas as requisições com prioridade alta sem preempção é o suficiente para o sistema, conforme indicado pelo fator de utilização do servidor, que se apresenta em 0,45, ou seja, uma ociosidade de 55\%. Ademais, se aumentar o número de servidores para esse atendimento a ociosidade aumenta mais, sem ganhos, haja vista a demanda de prioridades para perícias documentoscópicas ser baixa.

Visando a complementar a análise em questão, tem-se a Tabela 4, a seguir, que compara e evidencia a diferença entre os tempos médios de cada etapa no sistema, em dias úteis.

Tabela 4 - Comparação nos tempos de cada etapa do sistema de atendimento de prioridade alta e o sistema geral de atendimento

\begin{tabular}{c|c|c|c|c} 
Classe & $\begin{array}{c}\text { Chegada - } \\
\text { Início do } \\
\text { atendimento }\end{array}$ & $\begin{array}{c}\text { Tempo - } \\
\text { Atendimento }\end{array}$ & $\begin{array}{c}\text { Término - } \\
\text { Atendimento - } \\
\text { Arquivamento }\end{array}$ & $\begin{array}{c}\text { Tempo - } \\
\text { Sistema }\end{array}$ \\
\hline $\begin{array}{c}\text { Sistema de atendimen- } \\
\text { to de prioridade alta }\end{array}$ & 1,43 & 2,49 & 3 & 6,92 \\
\hline $\begin{array}{c}\text { Sistema geral de aten- } \\
\text { dimento }\end{array}$ & $\begin{array}{c}9,7 \\
\text { Fonte: elaborado pelo autor }\end{array}$ & 7,51 & 19,63
\end{tabular}

Feita esta análise com a prioridade, pode-se analisar separadamente as prioridades baixas a partir deste momento, onde $\lambda$ é igual a 1,003 , e dimensionar a equipe para o restante das chegadas. Conforme planilha do Microsoft Excel, elaborada por Hillier e Lieberman (2013) no modelo M/M/c, têm-se os seguintes resultados na Tabela 5.

Tabela 5 - Modelo M/M/c - 4 servidores

\begin{tabular}{ccc} 
Descrição & Símbolo & Valor \\
\hline Quantidade de servidores (c) & & 4 \\
Número de clientes esperando & $\mathrm{E}(\mathrm{L})$ & 2,921 \\
Comprimento da fila & $\mathrm{E}(\mathrm{Lq})$ & 0,475 \\
Tempo de espera no sistema (em dias úteis) & $\mathrm{E}(\mathrm{W})$ & 2,913 \\
Tempo de espera na fila (em dias úteis) & $\mathrm{E}(\mathrm{Wq})$ & 0,474 \\
Fator de utilização do servidor & $\mathrm{E}(\mathrm{P})$ & 0,611 \\
\hline Fonte: elaborado pelo autor & &
\end{tabular}


Conforme exposto, é possível observar que a opção para atendimento da classe de prioridade baixa com quatro servidores possui ótimos indicadores: 2,921 clientes esperando no sistema, 2,913 de tempo de espera no sistema, o comprimento da fila e o tempo de espera na fila são menores que um dia, com 0,475 e 0,474, respectivamente. Apresentando, ainda, fator de utilização por servidor 0,611 , ou seja, ociosidade de aproximadamente $40 \%$, menor que a encontrada na classe de prioridade alta (55\%).

Assim, cabe à chefia do Setec da unidade pericial avaliar o custo-benefício da manutenção de seis PCFs realizando exames documentoscópicos. Vale destacar que na presente análise não se levou em conta a utilização dos servidores para outras atividades periciais e policiais. O Gráfico 8 apresenta a distribuição de probabilidade da existência de requisições na fila considerando quatro servidores.

Gráfico 8 - Distribuição de probabilidade em função do número de clientes na fila $\mathrm{M} / \mathrm{M} / \mathrm{c}$, para $\mathrm{c}=4$

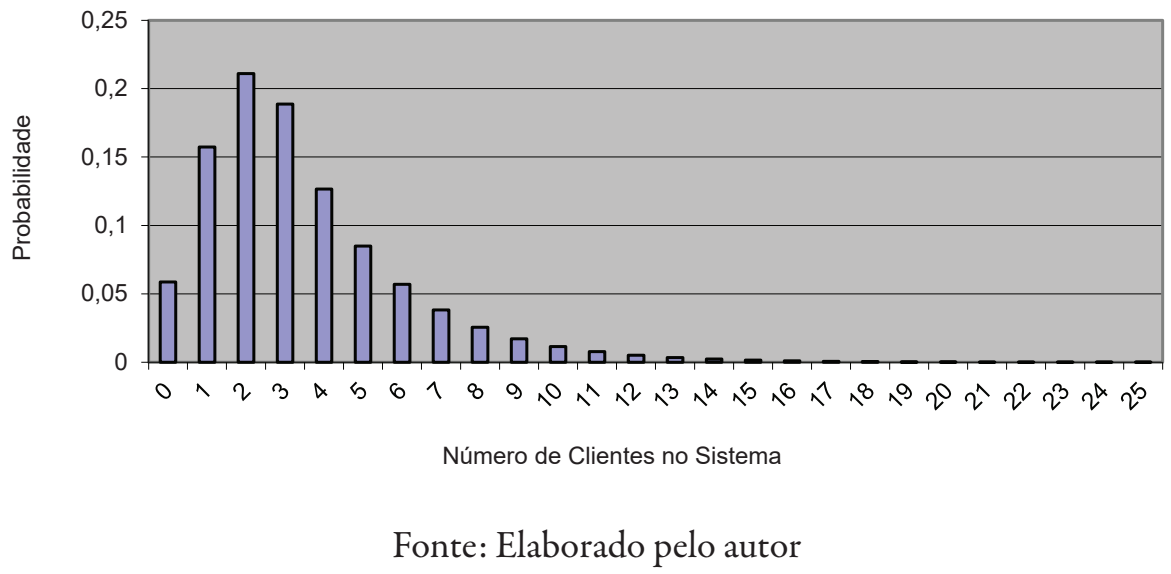

Nesse modelo, a probabilidade de se ter mais de dois clientes na fila reduz a cada incremento de cliente, chegando a ser menor que $5 \%$ a partir de sete clientes na fila.

In concluso, observa-se que:

Quando se reduz o número de servidores, $p$ aumenta e o tamanho da fila também aumenta.

a) No sistema em questão, o tempo de resposta é muito importante; portanto, a fila deve ser pequena. $\mathrm{O} \rho$ próximo a 0,6 é o ideal, ou seja, com quatro servidores. 
b) A centralização é melhor que a descentralização; portanto, mesmo que a fila cresça, nesse caso, o ganho com a especialização do atendimento tende a reduzir a fila e aumentar a produtividade do PCF.A manutenção da fila única fortalecerá a melhora no atendimento.

c) O custo de aumento do comprimento das filas e dos tempos de espera são insignificantes perante o ganho de produtividade com quatro servidores.

d) O tempo de espera no sistema deve ser menor que o tempo legal de dez dias estabelecido no CPP para realização da perícia.

\section{AnÁlise de Sensibiliddade}

Neste tópico, foi realizado o estudo do comportamento do sistema pericial de atendimento de perícia documentoscópica, aplicando o modelo $\mathrm{M} / \mathrm{M} / \mathrm{c}$ para outras situações reais, possibilitando dimensionar a equipe de atendimento, conforme a mudança de parâmetros.

\section{$4.1 \mathrm{M} / \mathrm{M} / \mathrm{C}$ COM PRIORIDADES EM $20 \%$ E $\lambda$ EM 1,10}

Tal modelagem tem como foco verificar a reação do sistema ao mudar a chegada de eventos com prioridade alta. Para a primeira simulação, foram definidos os seguintes parâmetros:

a) quanto às taxas de chegadas prioritárias: em 20\% do total;

b) quanto ao tempo de atendimento: foi mantida a média calculada real, que ficou em 2,41 dias para uma requisição; e

c) a taxa de chegada geral foi mantida em 1,10.

Fazendo uso dos cálculos em planilha do Microsoft Excel, na Tabela 6, a seguir, têm-se os seguintes resultados, com base no modelo Hillier e Lieberman (2013):

Tabela 6 - Modelo M/M/c - duas classes de prioridade (alta - 20\% e baixa - 80\%)

$$
\lambda=1,10 \text {. }
$$




\begin{tabular}{|c|c|c|c|c|}
\hline Descrição & Símbolo & $\begin{array}{l}\text { Prioridade } \\
\text { Alta }\end{array}$ & $\begin{array}{l}\text { Prioridade } \\
\text { Baixa }\end{array}$ & Total \\
\hline$\lambda$ total & & 0,22 & 0,88 & 1,10 \\
\hline Número de clientes esperando & $\mathrm{E}(\mathrm{L})$ & 0,136 & 0,696 & \\
\hline Comprimento da fila & $\mathrm{E}(\mathrm{Lq})$ & 0,045 & 0,333 & \\
\hline $\begin{array}{c}\text { Tempo de espera no sistema (em } \\
\text { dias úteis) }\end{array}$ & $\mathrm{E}(\mathrm{W})$ & 0,619 & 0,792 & \\
\hline $\begin{array}{c}\text { Tempo de espera na fila (em dias } \\
\text { úteis) }\end{array}$ & $\mathrm{E}(\mathrm{Wq})$ & 0,206 & 0,378 & \\
\hline Fator de utilização do servidor & $\mathrm{E}(\mathrm{P})$ & & & 0,454 \\
\hline
\end{tabular}

Fonte: elaborado pelo autor

Conforme exposto, é possível observar que as consequências para a fila quando as chegadas de classe prioritária aumentam para $20 \%$ do total são pequenas. Os indicadores acima na classe prioritária alta e baixa se mantêm muito próximos do mesmo nível de estabilidade do sistema quando as altas prioridades são $9 \%$, mantendo, inclusive, a mesma condição de ter um servidor para atender essas prioridades.

No entanto, ao reduzir o $\lambda$ para 0,88 das prioridades baixas, é possível observar isoladamente que pode ser mantida a mesma equipe para o atendimento da classe de baixa prioridade calculada com $90 \%$, conforme planilha do Microsoft Excel elaborada por Hillier e Lieberman (2013), no modelo M/M/c da Tabela 7 abaixo:

Tabela 7 - Modelo M/M/c - 4 servidores

$\begin{array}{ccc}\text { Descrição } & \text { Símbolo } & \text { Valor } \\ \text { Quantidade de servidores (c) } & & 4 \\ \text { Número de clientes esperando } & \mathrm{E}(\mathrm{L}) & 2,391 \\ \text { Comprimento da fila } & \mathrm{E}(\mathrm{Lq}) & 0,245 \\ \text { Tempo de espera no sistema (em dias } & \mathrm{E}(\mathrm{W}) & 2,717 \\ \text { úteis) } & \mathrm{E}(\mathrm{Wq}) & 0,278 \\ \text { Tempo de espera na fila (em dias úteis) } & \mathrm{E}(\mathrm{P}) & 0,536\end{array}$

Fonte: elaborado pelo autor

Conforme exposto, para manter o número total de cinco peritos na equipe de atendimento, observa-se que os indicadores do atendi- 
mento da classe de prioridade baixa melhoram um pouco: 2,391 clientes esperando no sistema; 2,717 de tempo de espera no sistema; o comprimento da fila e o tempo de espera na fila também reduzem para 0,245 e 0,278 , respectivamente. No entanto, o fator de utilização por servidor reduz para 0,536 , ou seja, a ociosidade aumenta para aproximadamente $46 \%$, próximo da encontrada na classe de prioridade alta (55\%).

\subsection{M/M/C COM PRIORIDADES EM $20 \%$ E $\lambda$ EM 3,0}

Para a segunda simulação, foram definidos os seguintes parâmetros:
a) quanto às taxas de chegadas prioritárias: em 20\%;
b) quanto ao tempo de atendimento: foi mantida a média cal- culada real, que ficou em 2,42 dias pra uma requisição; e
c) a taxa de chegada geral foi aumentada para $\lambda=3$.

Fazendo uso dos cálculos em planilha do Microsoft Excel, na Tabela 8, a seguir, tem-se os seguintes resultados, com base no modelo de Hillier e Lieberman (2013):

Tabela 8 - Modelo M/M/c - duas classes de prioridade (alta - 20\% e baixa - 90\%) $\lambda=3,0$.

\begin{tabular}{|c|c|c|c|c|}
\hline Descrição & Símbolo & $\begin{array}{l}\text { Prioridade } \\
\text { Alta }\end{array}$ & $\begin{array}{l}\text { Priorida- } \\
\text { de Baixa }\end{array}$ & Total \\
\hline$\lambda$ total & & 0,60 & 2,40 & 3,00 \\
\hline Número de clientes esperando & $\mathrm{E}(\mathrm{L})$ & 0,315 & 1,698 & \\
\hline Comprimento da fila & $\mathrm{E}(\mathrm{Lq})$ & 0,067 & 0,706 & \\
\hline $\begin{array}{l}\text { Tempo de espera no sistema (em dias } \\
\text { úteis) }\end{array}$ & $\mathrm{E}(\mathrm{W})$ & 0,525 & 0,707 & \\
\hline $\begin{array}{l}\text { Tempo de espera na fila (em dias } \\
\text { úteis) }\end{array}$ & $\mathrm{E}(\mathrm{Wq})$ & 0,111 & 0,294 & \\
\hline Fator de utilização do servidor & $\mathrm{E}(\mathrm{P})$ & & & 0,619 \\
\hline
\end{tabular}

Fonte: elaborado pelo autor

Conforme exposto, é possível perceber que, para ter estabilidade no sistema e no atendimento da classe de prioridade alta, é necessário elevar o número de atendentes da classe prioritária alta para dois 
peritos, obtendo, assim, resultados excelentes, pois todos os indicadores são menores que um dia, isso com o fator de utilização do servidor próximo a 0,619 .

Nesse caso, ao alterar o $\lambda$ do sistema geral de atendimento (baixa prioridade) para 0,88 , pode-se verificar a necessidade de aumento do número de peritos nessa equipe, alterando a quantidade total para 11. Conforme planilha do Microsoft Excel elaborada por Hillier e Lieberman (2013), no modelo $\mathrm{M} / \mathrm{M} / \mathrm{c}$, têm-se os seguintes resultados na Tabela 9 a seguir:

Tabela 9 - Modelo M/M/c - 9 servidores

\begin{tabular}{|c|c|c|}
\hline Descrição & Símbolo & Valor \\
\hline Quantidade de servidores (c) & & 9 \\
\hline Número de clientes esperando & $\mathrm{E}(\mathrm{L})$ & 6,178 \\
\hline Comprimento da fila & $\mathrm{E}(\mathrm{Lq})$ & 0,325 \\
\hline $\begin{array}{c}\text { Tempo de espera no sistema (em } \\
\text { dias úteis) }\end{array}$ & $\mathrm{E}(\mathrm{W})$ & 2,574 \\
\hline $\begin{array}{c}\text { Tempo de espera na fila (em dias } \\
\text { úteis) }\end{array}$ & $\mathrm{E}(\mathrm{Wq})$ & 0,135 \\
\hline $\begin{array}{l}\text { Fator de utilização do servidor } \\
\text { Fonte: } \mathrm{e}\end{array}$ & $\begin{array}{l}\mathrm{E}(\mathrm{P}) \\
\text { lo pelo autor }\end{array}$ & 0,65 \\
\hline
\end{tabular}

Conforme exposto, será necessário aumentar o número de peritos para 11 na equipe de atendimento, porque foi observada alteração nos indicadores do atendimento da classe de prioridade baixa: 6,178 clientes esperando no sistema; 2,574 de tempo de espera no sistema; o comprimento da fila e o tempo de espera na fila também mudaram para 0,325 e 0,135, respectivamente. No entanto, o fator de utilização por servidor aumentou para 0,65 , ou seja, a ociosidade reduz para aproximadamente $35 \%$, estando com $20 \%$ a menos em relação à encontrada na classe de prioridade alta (55\%).

\section{CONSIDERAÇÕES FINAIS}

No presente estudo, foram introduzidos os principais problemas na gestão do processo de atendimento da perícia documentoscópica na Polícia Federal - PF, a taxa de chegadas e o dimensionamento 
da equipe de atendimento, que em grande parte dos estudos sobre a Teoria das Filas foca nos gargalos e nos tempos de atendimento.

A partir dos resultados é possível avaliar e modificar, com justificativa científica, o dimensionamento da equipe para atender as requisições estudadas.

Portanto, torna-se imprescindível que o gestor tenha à disposição, semanalmente, a taxa de chegada das requisições, para que possa definir o número de peritos que atenderá tal demanda e, assim, evitar gargalos na fila e atendimento superior ao prazo legal.

Importante destacar a reação de cada fila (alta prioridade e baixa prioridade) quando se modifica a taxa de chegada para cada um. Percebe-se que no sistema de nascimento-e-morte, o impacto maior ocorre no sistema de baixa prioridade, pois com a elevação das chegadas de alta prioridade torna-se necessário deslocar servidores para esse tipo de atendimento.

A simulação desse sistema apresentou diversas vantagens, quais sejam:

a) compreender melhor o funcionamento do atual sistema e melhorá-lo;

b) confrontar resultados simulados e reais;

c) permitir analisar um novo sistema antes de sua real implantação, em virtude da análise de sensibilidade;

d) melhorar a operação do sistema já existente.Este estudo permite avançar nos conceitos dos registros do Siscrim, corrigindo cálculos que no sistema se apresentam como tempo de atendimento, onde, na verdade, o correto é tempo de sistema, podendo evoluir para todos os demais indicadores da fila requisições periciais, induzindo, dessa forma, que o sistema apresenta fragilidades institucionais.

Outra importante medida para melhoria da gestão do sistema estudado é buscar a efetividade do sistema usando como referência os 
resultados do modelo $\mathrm{M} / \mathrm{M} / \mathrm{c}$ com quatro servidores, no qual: a medida de tempo que um cliente é forçado a esperar na fila e no sistema seja, respectivamente, de 0,711 e 3,15 dias; e o acúmulo de clientes na fila e no sistema seja de 0,783 e 3,465, respectivamente, além de elevar o fator de utilização do servidor para 67\%. Para finalizar, vale destacar o resultado das simulações no sistema de nascimento-e-morte aqui analisado:

a) O aumento das chegadas causa impacto diretamente no tamanho das filas e no tempo que a requisição permanece no sistema, ou seja, quanto maior a chegada, mais tempo a requisição estará na fila, elevando o número de pendências.O aumento das chegadas de requisições classificadas como alta prioridade impacta diretamente o atendimento de baixa prioridade, ou seja, os tempos na fila dos atendimentos de baixa prioridade aumentam.Com as alterações supramencionadas, torna-se imprescindível que o gestor tenha à disposição servidores para atender às variações de demanda, buscando promover a estabilidade do sistema. Após a identificação do gargalo na etapa pós-atendimento pericial e antes da saída do sistema pericial de atendimento, durante o estudo, a chefia do Setec implementou uma divisão na secretaria em duas: entrada e saída, com um servidor para cada, agilizando o processo de conferência, lançamentos no sistema, saída do laudo com o material periciado e entrega do laudo com maior celeridade.

Para finalizar, por ser inédito este estudo, sugere-se aprofundar a aplicação da Teoria das Filas em todas as demandas da perícia (áreas), bem como no processo de atendimento de uma investigação policial para resolver os congestionamentos, tanto no atendimento prioritário, como no atendimento geral.

Roosevelt Alves Fernandes Leadebal Junior

Mestrado em Engenharia de Produção

Universidade Federal de Pernambuco - DF

Perito Criminal Federal 


\title{
Application of the Theory of The Rows, With Priorities, TO THE DOCUMENT Statutory Area of a Superintendence of The Federal Police
}

\begin{abstract}
The present study is intended to analyze the behavior of the system of service of the document-documentary service in a unit of the federal police expertise, observing its ranges of high and low priority attendance. Therefore, the current system was modeled and tested in the model to perceive the system behavior the period analyzed by the modeling composed january 2017 to june 2017. Arrivals and services were not rejected by the adhesion tests (qui -square). The results obtained provide a tool for analysis and forecasting management measures necessary to avoid congestion in the system. In the meaning of amendments to priority arrangements, the search for stability of the system $(\mathrm{m} / \mathrm{m} / \mathrm{c})$ could dimension the service team necessary to react that change.
\end{abstract}

KEYWORDS: Federal police. Federal forensic scientist. Queuing theory. Priorities.

\section{Aplicación de LA Teoría de LA Cola, con Prioridades, al Área de Pericia Documentostocópica de UNA Superintendencia de Policía Federal}

\section{RESUMEN}

El presente trabajo se propone analizar el comportamiento del sistema de atención del peritaje documental en una unidad del Peritaje de la Policía Federal, observando sus líneas de servicio de alta y baja prioridad. Para ello, se modeló el sistema actual y se realizaron pruebas sobre el modelo para comprender el comportamiento del sistema en el período analizado por la modelización, que comprende de enero de 2017 a junio de 2017. Las llegadas y asistencia no fueron rechazadas por las pruebas de adherencia ( chi-cuadrado). Los resultados obtenidos proporcionan una herramienta de análisis y previsión de medidas de gestión, necesaria para evitar cuellos de botella en el sistema. A medida que demuestran cambios en las llegadas prioritarias, la búsqueda de estabilidad 
del sistema ( $\mathrm{m} / \mathrm{m} / \mathrm{c})$ logra dimensionar el equipo de servicio necesario para reaccionar ante ese cambio.

Palabras Clave: Policía Federal. Pericia Penal Federal. Teoría de colas. Prioridades.

\section{REFERÊNCIAS}

ANDRADE, E. L. Introdução à pesquisa operacional: Métodos e modelos para a análise de decisão. 2. ed. Rio de Janeiro: LTC, 2000.

BRASIL. Polícia Federal. Diretoria Técnico-Científica. Sistema de Informações em Bases Criminais. Brasília: Polícia Federal, 2018.

CHWIF, L.; MEDINA, A. Modelagem e simulação de eventos discretos: Teoria \& aplicações. São Paulo: Elsevier, 2014.

HILLIER, F. S.; LIEBERMAN, G. J. Introdução à pesquisa operacional. 9.ed. Porto Alegre: AMGH, 2013.

MOREIRA, D. A. Pesquisa Operacional: curso introdutório. 2.ed. São Paulo: Cengage Learning, 2010.

PRADO, D. Teoria das Filas e da simulação. 2.ed. Belo Horizonte: Editora de Desenvolvimento Gerencial, 2004.

R CORE TEAM. $R$ : A language and environment for statistical computing. Vienna: R Foundation for Statistical Computing, 2018.

SANTOS, M. Apostila de pesquisa operacional da Universidade Estadual do Rio de Janeiro. Rio de Janeiro: UERJ, 2003.

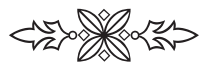

